\title{
Stability Analysis for Yield and Yield Attributing Characters among Advanced Stabilized Promising Lines in Cowpea [Vigna unguiculata (L.) Walp.]
}

\author{
Sanjeev K. Deshpande* and A.R. Vishwas
}

Department of Genetics and Plant Breeding, UAS, Dharwad, Karnataka - 580005, India

*Corresponding author

\begin{abstract}
A B S T R A C T
Keywords

Genotype $\times$

environment

interaction, Legume,

Promising lines,

Stable

Article Info

Accepted:

06 September 2018

Available Online:

10 October 2018

Cowpea is an important legume in many developing countries and it is a major vegetable source of protein for human consumption especially in Africa and Asia countries including India. Cowpea is grown in almost all the agro ecological zones in India, the performance of genotypes exhibits a wide range of variation within and between environments because of genotype $\times$ environment interaction, so in the present study the seventeen promising advanced lines of cowpea and three checks were evaluated for yield and yield attributing traits across three environments $\mathrm{E}_{1}, \mathrm{E}_{2}$, and $\mathrm{E}_{3}$. Stability analysis was carried out using Eberhart and Russell (1966) model. Based on stability parameters, the $\mathrm{F}_{6}$ stabilized lines of DC $15 \times$ CPD 118 and DC15 $\times$ DCS 47-1-1 were identified as most stable genotypes for seed yield. Likewise $\mathrm{F}_{6}$ Promising lines C $152 \times$ IC 202860, DC $15 \times$ CPD 118 and GC $3 \times$ CPD 115 for pod length, C $152 \times$ GL3, DC16 and C $152 \times$ IC 202860 for pod number, C $152 \times$ P 206, C $152 \times$ DCS 5-3-20, DC $15 \times$ Job 129 and DCS 47-1 × DC 15 for number of number of seeds per pod were found to be stable. All the superior stabilized families can be further tested in different locality to ascertain their superiority in different agro climatic regions.
\end{abstract}

\section{Introduction}

Cowpea [Vigna unguiculata (L.) Walp.] is an important legume in many developing countries including india (Adam and Baidoo, 2008). It is a major vegetable source of protein for human consumption especially in Africa and India. Cowpea seeds contain about 25\% protein, making it extremely valuable in areas where many people cannot afford protein foods from animal sources namely meat and fish (Deshpande et al., 2011). It can be a unique dietary protein source for poor people and is one of the cheapest source (Rangel $e t$ al., 2003). Cowpea is a drought tolerant crop and thrives in warm weather and well adapted to the drier regions of the tropics like India (Singh, 2005). Cowpea can be grown in almost all the agro ecological zones in India. The performance of genotypes exhibits a wide range of variation within and between environments because of genotype $x$ environment interaction (Uttam et al., 2014). When interaction between genotype and environment exists, it may cause a difference in relative ranking of varieties when they are 
compared over a series of environments. This makes the efforts in cowpea varietal development more challenging and skillful. Phenotypically stable genotypes are of great importance because the environmental conditions vary from season to season and year to year (Silva et al., 2016). The adaptability and stability of genotypes deserve attention in breeding program. So in this context the present investigation was carried to identify the stable cowpea genotypes across the varied environments.

\section{Materials and Methods}

The experiment was conducted at 3 locations such as Agriculture Research Station Malagi $\left(E_{1}\right)$ with Red soil, and protective irrigation during Rabi 2017, Agriculture Research Station, Mugad $\left(\mathrm{E}_{2}\right)$ with Sandy loamy soil in paddy fallows in Rabi 2017 and Main Agriculture Research Station, University of Agricultural Sciences, Dharwad $\left(\mathrm{E}_{3}\right)$ with deep black soil and assured rainfall (transitional zone) during Summer 2018.

Materials used in the study were 17 promising advanced stabilized $\mathrm{F}_{6}$ lines of different crosses combinations generated at the Department of Genetics and Plant Breeding, UAS Dharwad, along with three checks such as DC 15, DC 16 and DCS 47-1. Stabilized lines and checks were grown in all three locations by following RCBD design with two replications along with normal agronomic practices.

Results were analyzed according to stability model given by Eberhart and Russell model (1966). The model involves the estimation of three stability parameters viz., mean, regression coefficient and deviation from regression, and which are defined by the mathematical formula as given below.

$Y_{i j}=\mu_{i}+b_{i} I_{j}+S_{i j}$
Where,

$Y_{i j}=$ Mean of the $i^{\text {th }}$ genotype at the $j^{\text {th }}$ environment

$\mu_{\mathrm{i}}=$ Mean of $i^{\text {th }}$ genotype over all environments

$b_{i}=$ Regression coefficient that measures the response of $i^{\text {th }}$ genotype to varying environments

$\mathrm{I}_{\mathrm{j}}=$ Environmental index obtained by subtracting the grand mean from the mean of all genotypes at the $\mathrm{j}^{\text {th }}$ environment

$S_{i j}=$ Deviation from regression of the $i^{\text {th }}$ genotype at the $\mathrm{j}^{\text {th }}$ environment

Where,

Environment index $=\mathrm{I}_{\mathrm{j}}=$ environment mean grand mean

In this model the variance due to environments and genotype $\times$ environment are partitioned into environment (linear), genotype $\times$ environment (linear) and deviation from the regression coefficient. Observations were recorded on five competitive plants in respect of three important traits viz., pod length, number of number of pods per plantand number of number of seeds per pod, seed yield $\left(\mathrm{kg} \mathrm{ha}^{-1}\right)$ was recorded on plot basis. The stability parameter mean provides a measure of the performance of a genotype as compared to other entries. The $b_{i}$ and $S^{2} d_{i}$ values are the measure of the $G \times E$ interactions. In general if $\mathrm{G} \times \mathrm{E}$ interaction is non-significant or predominantly linear as compared to its non-linear component, the prediction of stability of a genotype over environments becomes more precise and accurate. As per the Eberhart and Russell (1966) model of stability, components $S^{2} d_{i}$ measure the predictability whereas $b_{i}$ 
measures the stability. Stability of a genotype can be predicted more precisely if $\mathrm{G} \times \mathrm{E}$ interaction and $S^{2} d_{i}$ values are non-significant. They defined an ideal genotype as the one having highest mean value with a regression coefficient $\left(b_{i}\right)$ equal to unity and deviation from regression $\left(\mathrm{S}^{2} \mathrm{~d}_{\mathrm{i}}\right)$ close to zero. They further suggested that genotypes could be classified as below average stable performing only in favorable environments $\left(b_{i}>1\right)$, above average stable that are adapted specifically to poor environment $\left(b_{\mathrm{i}}<1\right)$ and average stable performing in most of the environment.

\section{Results and Discussion}

The analysis of variance showed highly significant mean sum of squares (MSS) for genotypes and environments for all the characters viz., pod length, number of pods per plant, number of seeds per pod and seed yield $\left(\mathrm{kg} \mathrm{ha}{ }^{-1}\right)$ which inferred the presence of variation among genotypes and environments. The genotypes $x$ environment interactions were significant for all traits which revealed that genotypes under study are having significant differential response to the changing environments. Further analysis of environment + (genotype $\times$ environment) component showed that it was significant for all the traits studied. Partitioning of this variation into linear and non-linear components revealed that the mean sum of square due to environment (linear) was significant for all the characters. The significant mean sum of squares confirms that the environments were random and different and they exercised influence on the expression of the traits. This variation could have arisen due to the linear response of the regression of the cultivar to the environment. The mean sums of squares due to the $\mathrm{G} \times \mathrm{E}$ (linear) were significant for the all characters. This revealed that the behavior of the genotypes could be predicted over the environments more precisely and accurately as the $\mathrm{G} \times \mathrm{E}$ interaction was the outcome of the linear function of the environmental components.

The non-linear component arising due to the heterogeneity measured as mean square due to the pooled deviation was significant for pod number and seed yield $\left(\mathrm{kg} \mathrm{ha}^{-1}\right)$ revealed the presence of non-linear response of the genotypes to the changing environment for these traits. The significance of pooled deviation for the pod number and seed yield $\left(\mathrm{kg} \mathrm{ha}{ }^{-1}\right)$ confirms contribution of the nonlinear component to the total $\mathrm{G} \times \mathrm{E}$ interaction for them. The genotypes differed with respect to the stability of these traits making its prediction more difficult. However, the magnitude of linear component i.e. environment (linear) and genotype $x$ environment (linear) was many times higher than the non-linear component (pooled deviation) for most of the characters. This trend revealed that the prediction of stability could be reliable though it may get affected to some extent. The results obtained in the present study are in agreement with the finding of (Ali et al., 2004), (Akande, 2007) and (Adewale et al., 2010). The mean of the characters, namely, pod length, number of pods per plant, number of seeds per pod and seed yield $\left(\mathrm{kg} \mathrm{ha}^{-1}\right)$, along with the two stability parameters, viz., regression coefficients $\left(b_{i}\right)$ and deviation from regression $\left(\mathrm{S}^{2} \mathrm{~d}_{\mathrm{i}}\right)$ are presented in Table 2 .

It was clear from environmental indices (-225 to 426) that locations were highly distinct from one another in affecting seed yield $(\mathrm{kg}$ $\left.\mathrm{ha}^{-1}\right)$. So the extent of influence of environment was significant (Table 1). The average seed yield recorded over all three environments was $1821.74 \mathrm{~kg} \mathrm{ha}^{-1}$ (Table 2). Due to the highest environmental indices and site mean in $\mathrm{E}_{1}$ (ARS, Malagi), it found to be suitable environment for per se seed yield compared to other two environments. The $\mathrm{F}_{6}$ genotype C $152 \times$ GL 3 was highest yielder 
$\left(2297.26 \mathrm{~kg} \mathrm{ha}^{-1}\right)$ while, the $\mathrm{F}_{6}$ line $(\mathrm{GC} 3 \times$ CPD 115) was lowest (1392.61 $\mathrm{kg} \mathrm{ha}^{-1}$ ) among all the 20 genotypes studied (Table 2).

The genotypes which gave higher mean seed yield over three environments were C $152 \times$ GL3 (2297.3 $\left.\mathrm{kgha}^{-1}\right)$, DC $15 \times$ CPD 118 $\left(2125.14 \mathrm{kgha}^{-1}\right), \quad$ DC15 $\times$ SHUBRA $\left(2108.847 \mathrm{~kg} \mathrm{ha}^{-1}\right)$, C $152 \times$ IC 202860 $\left(2064.23 \mathrm{~kg} \mathrm{ha}^{-1}\right)$, DC15 $\times$ DCS 47-1-1 $\left(2029.5 \mathrm{~kg} \mathrm{ha}^{-1}\right), \mathrm{V} 118 \times$ IC257437 (1927.398 $\left.\mathrm{kg} \mathrm{ha}^{-1}\right)$, DC15 $\times$ DCS 47-1-2 (1913.845 kg $\left.\mathrm{ha}^{-1}\right), \mathrm{C} 152 \times \mathrm{P} 206\left(1889.83 \mathrm{~kg} \mathrm{ha}^{-1}\right)$ and DC $15 \times$ C $152\left(1888.925 \mathrm{~kg} \mathrm{ha}^{-1}\right)$. However the results indicated that the genotypes DC $15 \times$ CPD 118 and DC $15 \times$ DCS 47-1-2 were found to be most stable since these showed regression coefficient values near to unity, least non-significant deviation from regression and higher seed yield (Table 2).

The highly unstable genotypes were DC $15 \times$ DCS 47-1-1, GC $3 \times$ CPD 115 and DCS 47-1 $\times$ DC 15 , since they indicated significant deviation from regression. The genotypes DC $15 \times$ SHUBRA, C $152 \times$ IC 202860 and V 118 $\times$ GL3 showed $b_{i}$ values greater than unity and non-significant deviation from regression. It means these genotypes could perform better under favorable environments only. The genotypes which could perform better under poor environments were C $152 \times$ GL 3 and V $118 \times$ IC257437, since these have $b_{i}$ values significantly deviating from unity. The genotypes DC $15 \times$ DCS 47-1-1, DC $15 \times$ SHUBRA found to be specifically adapted to the favorable environment $\mathrm{E}_{1}$ (ARS Malagi); likewise genotypes DC15 $\times$ CPD 115 specifically suitable for paddy fallows (ARS, Mugad) whereas the genotypes such as V118 $\times$ IC257437 and C $152 \times$ GL 3 were found to be adopted particularly to $\mathrm{E}_{3}$ (MARS, Dharwad).

Locations varied with regard to pod length as seen from the environmental indices -1.10 to
1.52 (Table 1), so the character was much affected by environment. The average pod length over three environments is $16 \mathrm{~cm}$ (Table 2) and on the basis of site mean and environment indices $\mathrm{E}_{1}$ (Malagi) was most favorable for this trait compare to $E_{2}$ and $E_{3}$. The $\mathrm{F}_{6}$ line $\mathrm{C} 152 \times$ IC 202860 exhibited the longest pods $(17.79 \mathrm{~cm})$ while, the check DC 16 was having the shortest pods $(14.34 \mathrm{~cm})$ among all genotypes studied in all environments (Table 2).

While considering the genotypes suitable for breeding of pod length, the genotypes namely, C152 × IC 202860, DC15 × DCS 47-1-3, DC15(Check), C $152 \times$ GL 3, DC15 $\times$ DCS 47-1-2, DC $15 \times$ C 152, V $118 \times$ IC257437, DC $15 \times$ CPD 118 and GC $3 \times$ CPD 115 showed higher mean. However from stability point of view, the genotypes C $152 \times$ IC 202860, DC $15 \times$ CPD 118 and GC $3 \times$ CPD 115 were found most stable since they showed regression coefficient value $(1.54,1.11,1.49)$ near to unity, least non-significant deviation from regression (Table 2). The genotypes which showed $b_{i}$ value greater than unity and non-significant deviation from regression were DC15 and DC $15 \times \mathrm{C} 152$. This means that genotypes could perform better under favorable environments only and whereas genotype V $118 \times$ IC257437 perform better under poor environments since it has significant $b_{i}$ value lower than unity $(0.215)$.

With respect to number of pods per plants, locations have much effect as it was evident by having environmental indices ranging from -1.93 to 3.29 (Table 1). The average number of pods considering all environments is 28.66 (Table 2) and on the basis of location mean and environmental indices $\mathrm{E}_{1}$ (Malagi) was most suitable for this trait. The $\mathrm{F}_{6}$ progeny $\mathrm{C}$ $152 \times$ GL3 borne maximum number of pods per plant (35.62) whereas DC $15 \times$ GL 3 having minimum number of pods per plant (23.34) as shown in Table 2. 
Table.1 Mean values and environmental indices of yield and yield attributing characters across three environments of cowpea

\begin{tabular}{|c|c|c|c|c|c|c|c|c|c|c|c|c|c|}
\hline \multirow[t]{2}{*}{ SI. No. } & \multirow{2}{*}{$\begin{array}{c}\text { Genotype }\left(\mathrm{F}_{6}\right. \\
\text { Generation } \\
\text { of different crosses) }\end{array}$} & \multicolumn{3}{|c|}{ Seed yield $\left(\mathrm{kg} \mathrm{ha}^{-1}\right)$} & \multicolumn{3}{|c|}{ Pod length $(\mathrm{cm})$} & \multicolumn{3}{|c|}{ Number pods per plant } & \multicolumn{3}{|c|}{$\begin{array}{c}\text { Number of seeds per } \\
\text { pod }\end{array}$} \\
\hline & & $\mathbf{E}_{1}$ & $\mathbf{E}_{2}$ & $\mathbf{E}_{3}$ & $\mathbf{E}_{1}$ & $\mathbf{E}_{2}$ & $\mathbf{E}_{3}$ & $\mathbf{E}_{1}$ & $\mathbf{E}_{2}$ & $\mathbf{E}_{3}$ & $\mathbf{E}_{1}$ & $\mathbf{E}_{2}$ & $\mathbf{E}_{3}$ \\
\hline 1 & DC15 $\times$ DCS 47-1 -1 & 2839.5 & 1623.4 & 1625.7 & 16.46 & 14.865 & 14.385 & 33.205 & 22.665 & 21.165 & 12.625 & 13.33 & 14.33 \\
\hline 2 & C $152 \times$ P 206 & 2579.5 & 1606.4 & 1483.6 & 17.54 & 14.75 & 15.47 & 28.315 & 28.17 & 24.835 & 14.62 & 14.835 & 15.5 \\
\hline 3 & DC15 $\times$ SHUBRA & 3139.8 & 1565.9 & 1620.8 & 16.68 & 15.83 & 14.38 & 26.66 & 27.835 & 27.835 & 11.95 & 15.665 & 16.335 \\
\hline 4 & DC15 × DCS 47-1-2 & 2344.6 & 1739.3 & 1657.7 & 18.01 & 16.335 & 16.665 & 24.835 & 26.335 & 24.5 & 14.45 & 15.335 & 15.83 \\
\hline 5 & DC15 $\times$ DCS 47-1-3 & 1448.6 & 1697.8 & 1348.1 & 20.49 & 17.58 & 14.78 & 26.535 & 23 & 22.835 & 14.62 & 17.665 & 16 \\
\hline 6 & C $152 \times$ DCS 5-3-20 & 2222.2 & 1566.3 & 1555.3 & 14.78 & 16.215 & 14.885 & 31.38 & 26.67 & 27.5 & 13.615 & 14.665 & 15.5 \\
\hline 7 & V $118 \times$ GL3 & 3018.8 & 1242.7 & 1074.1 & 16.975 & 16.67 & 12.7 & 22.18 & 26.335 & 24.67 & 14.945 & 13.17 & 13.835 \\
\hline 8 & DC15 $\times$ Job 129 & 1427.7 & 1609.2 & 1233.2 & 15.79 & 12.7 & 14.785 & 22.925 & 25 & 24 & 14.68 & 13.165 & 14.835 \\
\hline 9 & DCS 47-1 $\times$ DC 15 & 2400.8 & 1374.8 & 1246.3 & 16.79 & 15.335 & 15.015 & 27.88 & 20.835 & 23.335 & 12.29 & 15.17 & 15.17 \\
\hline 10 & DC $15 \times$ GL3 & 2514.7 & 1434 & 1200.5 & 17.125 & 14.835 & 14.565 & 24.835 & 19.5 & & 13.46 & 15.165 & 13.335 \\
\hline 11 & V $118 \times$ IC 257425 & 2270.1 & 1419.9 & 1213 & 14.515 & 14.42 & 15.92 & 27.48 & 19.5 & 25.83 & 13.115 & 13.835 & 14.67 \\
\hline 12 & V $118 \times$ IC257437 & 2259.4 & 1694.7 & 1828.1 & 17.01 & 15.63 & 16.815 & 31.525 & 29.835 & 28.335 & 11.595 & 15.5 & 14.165 \\
\hline 13 & DC $15 \times$ C 152 & 2484.1 & 1511.7 & 1671 & 19.29 & 17.085 & 13.25 & 32.425 & 28.83 & 31.165 & 13.345 & 16.83 & 14.5 \\
\hline 14 & C $152 \times$ IC 202860 & 2979.8 & 1645.8 & 1567.1 & 19.96 & 17.885 & 15.53 & 41.915 & 29.33 & 29.83 & 13.79 & 16.335 & 14.5 \\
\hline 15 & GC $3 \times$ CPD 115 & 1160.1 & 1544.5 & 1473.2 & 18.68 & 14.22 & 15.35 & 34.425 & 37.5 & 31.835 & 12.015 & 13.835 & 13.835 \\
\hline 16 & DC $15 \times$ CPD 118 & 1843.4 & 2186.3 & 2345.7 & 18.125 & 15.335 & 15.415 & 39.08 & 31.33 & 26 & 11.79 & 15.335 & 13.83 \\
\hline 17 & C $152 \times$ GL3 & 2096.6 & 2469.3 & 2325.9 & 19.96 & 17.085 & 14.65 & 41.525 & 33.67 & 31.67 & 15.015 & 14.17 & 15.165 \\
\hline 18 & DC15 (Check) & 2231 & 1412.3 & 1485.9 & 21.77 & 15.15 & 15.15 & 39.915 & 29.665 & 27.835 & 15.345 & 14.835 & 15 \\
\hline 19 & DC16 (Check) & 1896.7 & 1525.6 & 2000.2 & 16.01 & 13.58 & 13.43 & 41.425 & 32.335 & 31.67 & 13.945 & 12.165 & 12.33 \\
\hline \multirow[t]{3}{*}{20} & DCS 47-1 (Check) & 1798.3 & 1545.8 & 1978.3 & 14.665 & 16 & 14.88 & 40.615 & 27.67 & 24 & 14.27 & 14.5 & 14.165 \\
\hline & E. Indices & 426.04 & -200.97 & -225.06 & 1.529 & -0.427 & -1.102 & 3.294 & -1.36 & -1.934 & -0.756 & 0.445 & 0.311 \\
\hline & Site Mean & 2247.8 & 1620.8 & 1596.7 & 17.531 & 15.575 & 14.901 & 31.954 & 27.301 & 26.726 & 13.574 & 14.775 & 14.642 \\
\hline
\end{tabular}

$\mathrm{E}_{1}$ : Agriculture Research Station, Malagi (Red soil with protective irrigation).

$\mathrm{E}_{2}$ : Agriculture Research Station, Mugad (Sandy loamy soil and in paddy fallows field).

$\mathrm{E}_{3}$ : Main Research Station, UAS, Dharwad (Deep black soil and assured rainfal). 
Table.2 Stability parameters for different characters in cowpea genotypes

\begin{tabular}{|c|c|c|c|c|c|c|c|c|c|c|c|c|c|}
\hline \multirow[t]{2}{*}{ Sl. No. } & \multirow{2}{*}{$\begin{array}{c}\text { Genotype }\left(\mathrm{F}_{6}\right. \\
\text { Generation } \\
\text { of different crosses })\end{array}$} & \multicolumn{3}{|c|}{ Seed yield $\left(\mathrm{kg} \mathrm{ha}^{-1}\right)$} & \multicolumn{3}{|c|}{ Pod length (cm) } & \multicolumn{3}{|c|}{$\begin{array}{c}\text { Number of pods per } \\
\text { plant }\end{array}$} & \multicolumn{3}{|c|}{$\begin{array}{c}\text { Number of seeds per } \\
\text { pod }\end{array}$} \\
\hline & & Mean & $\mathbf{b}_{\mathbf{i}}$ & $S^{2}$ di & Mean & $\mathbf{b}_{\mathbf{i}}$ & $S^{2}$ di & Mean & $\mathbf{b}_{\mathbf{i}}$ & $S^{2}$ di & Mean & $\mathbf{b}_{\mathbf{i}}$ & $S^{2} d i$ \\
\hline 1 & DC15 $\times$ DCS 47-1-1 & 2029.55 & $1.89^{*}$ & $106826 *$ & 15.24 & 0.8 & 1.39 & 25.68 & $2.28 *$ & 5.8 & 13.428 & $2.059 *$ & 0.37 \\
\hline 2 & C $152 \times$ P 206 & 1889.83 & 1.62 & -104471 & 15.92 & 0.93 & -0.4 & 27.11 & 0.42 & 0.99 & 14.985 & 0.95 & 0.15 \\
\hline 3 & DC15 $\times$ SHUBRA & 2108.85 & $2.41^{*}$ & 86327 & 15.63 & 0.78 & 0.93 & 27.44 & $0.23 *$ & 5.81 & 14.65 & $0.38 *$ & 1.34 \\
\hline 4 & DC15 $\times$ DCS 47-1-2 & 1913.85 & 1.01 & 8063 & 17 & 0.59 & -1.1 & 25.22 & -0.09 & -4.03 & 15.205 & 0.42 & 1.09 \\
\hline 5 & DC15 $\times$ DCS 47-1-3 & 1498.17 & -0.1 & 45931 & 17.62 & $2.01 *$ & 0.29 & 24.12 & 0.73 & 5.79 & 16.095 & $2.20 *$ & 0.74 \\
\hline 6 & C $152 \times$ DCS 5-3-20 & 1781.25 & 1.03 & 107881 & 15.29 & -0.2 & 0.25 & 28.52 & 0.85 & -4.94 & 14.593 & 1.56 & -0.01 \\
\hline 7 & V $118 \times$ GL3 & 1778.5 & $2.91^{*}$ & 103138 & 15.45 & 1.3 & 3.71 & 24.4 & -0.64 & 3.73 & 13.983 & -0.38 & -0.9 \\
\hline 8 & DC15 $\times$ Job129 & 1423.39 & 0.03 & 37460 & 14.43 & 0.65 & 2.02 & 23.98 & -0.3 & -5.12 & 14.227 & 1.48 & 0.7 \\
\hline 9 & DCS 47-1 x DC 15 & 1673.96 & 1.71 & $104161 *$ & 15.71 & 0.69 & 1.38 & 24.02 & 1.12 & 0.83 & 14.21 & 1.22 & -0.85 \\
\hline 10 & DC $15 \times$ GL3 & 1716.4 & 1.88 & 90273 & 15.51 & 1.02 & -1.3 & 23.34 & 0.34 & 14.66 & 13.987 & 0.08 & 1.3 \\
\hline 11 & V $118 \times$ IC 257425 & 1634.32 & 1.5 & 93385 & 14.95 & -0.4 & 0.59 & 24.27 & 0.85 & $17.68 *$ & 13.873 & -0.72 & -0.1 \\
\hline 12 & V $118 \times$ IC257437 & 1927.4 & $0.77 *$ & -96412 & 16.49 & $0.21 *$ & -0.5 & 29.9 & 0.52 & -5.09 & 13.753 & 2.51 & 1.29 \\
\hline 13 & DC $15 \times$ C 152 & 1888.93 & 1.39 & 89390 & 16.54 & $2.03 *$ & 0.84 & 30.81 & $0.44 *$ & 2.43 & 14.892 & 0.83 & 0.14 \\
\hline 14 & C $152 \times$ IC 202860 & 2064.23 & $2.15^{*}$ & 96325 & 17.79 & 1.55 & 0.47 & 33.69 & 1.46 & -3.96 & 14.875 & -1.31 & 1.23 \\
\hline 15 & GC $3 \times$ CPD 115 & 1392.61 & $0.542 *$ & $104424 *$ & 16.08 & 1.49 & 1.04 & 34.59 & 0.05 & $10.23 *$ & 13.228 & 0.93 & -0.88 \\
\hline 16 & Dc $15 \times$ CPD 118 & 2125.14 & 0.67 & 9770 & 16.29 & 1.12 & 1.02 & 32.14 & $2.18^{*}$ & 2.58 & 13.652 & 2.93 & -0.9 \\
\hline 17 & C $152 \times$ GL3 & 2297.26 & $0.46^{*}$ & 9602 & 17.23 & $1.89 *$ & -0.7 & 35.62 & 1.13 & 5.35 & 14.783 & 2.55 & 0.67 \\
\hline 18 & DC15 (Check) & 1709.71 & 1.22 & -102677 & 17.36 & $2.71 *$ & 0.39 & 32.47 & $2.26^{*}$ & -5.68 & 15.06 & 1.59 & -1.33 \\
\hline 19 & DC16 (Check) & 1807.53 & 0.19 & 6957 & 14.34 & 1.04 & 1.23 & 35.14 & 1.23 & 5.73 & 12.813 & 0.97 & 0.7 \\
\hline 20 & DCS 47-1 (Check) & 1774.11 & 0.04 & -13944 & 15.18 & -0.22 & 0.54 & 30.76 & 3.03 & -3.93 & 14.312 & -1.49 & 1.35 \\
\hline P. mean & & 1821.75 & & & 16 & & & 28.66 & & & 14.33 & & \\
\hline SE for mean & & 106.9 & & & 0.78 & & & 1.52 & & & 0.54 & & \\
\hline SE for $b_{i}$ & & & 0.3 & & & 0.57 & & & 0.53 & & & 0.82 & \\
\hline
\end{tabular}


The genotypes which showed higher mean values for number of pods per plant over three environments were C $152 \times$ GL3, DC16 (check), GC $3 \times$ CPD 115, C $152 \times$ IC 202860, DC15(check), DC $15 \times$ CPD 118, DC $15 \times$ C 152, DCS 47-1 (check) and V 118 $x$ IC257437. Out of them, the genotypes namely C $152 \times$ GL3, DC16 and C $152 \times$ IC 202860 were found stable since they showed regression values $(1.13,1.23$, and 1.46 respectively) near to unity, non-significant deviation from regression and higher mean (Table 2). The highly unstable genotypes were GC $3 \times$ CPD 115 and V $118 \times$ IC257425, since they indicated significant deviation from regression. The genotypes which showed $b_{i}$ value more than unity and non-significant deviation from regression were DC15 (check) and DC $15 \times$ CPD 118, so these genotypes could perform better under favorable environments only and performance these genotypes could be predicted. The genotype which could perform better under poor environments was DC $15 \times \mathrm{C} 152$ since it has $b_{i}$ less than unity and least nonsignificant deviation.

With respect to number of seeds per pod, the environmental indices ranged from -0.75 to 0.44 (Table 1) indicated significant variation across the three locations, whereas the average number of seeds per pod across all environments is 14.33. Since $\mathrm{E}_{2}$ (Mugad) was having higher site mean and environmental indices among three locations, so this environment is most favorable for number of number of seeds per pod. The highest number of number of seeds per pod (16.05) was observed in $\mathrm{F}_{6}$ line DC15 $\times$ DCS 47-1-3 while DC 16 (Check) had the lowest number of seeds per pod (12.81) as shown in Table 2.

While considering the genotypes suitable for breeding of number of seeds per pod, the genotypes namely, DC15 × DCS 47-1-3, DC15 × DCS 47-1-2, DC15(check), C $152 \times$
P 206, DC $15 \times$ C 152, C $152 \times$ IC 202860, C $152 \times$ GL3, DC15 $\times$ SHUBRA and C $152 \times$ DCS 5-3-20 showed good performance by having higher mean. However from stability point of view the genotypes C $152 \times \mathrm{P} 206, \mathrm{C}$ $152 \times$ DCS 5-3-20, DC $15 \times$ Job 129 and DCS $47-1 \times$ DC 15 were found most stable for number of seeds per pod since these showed regression coefficient values $(0.95$, $1.56,1.48,1.22$ respectively) near to unity, least non-significant deviation from regression and higher mean (Table 2).

The genotypes which showed $b_{i}$ values greater than unity and non-significant deviation from regression were DC15 $\times$ DCS 47-1-1 and DC15 $\times$ DCS 47-1-3. It means these genotypes perform better under favorable environments only and performance of these genotypes could be predicted. The genotype which performs better under poor environments was DC15 $\times$ SHUBRA since it has significant $b_{i}$ value less than unity $(0.38)$.

Thus it can be concluded that the $\mathrm{E}_{1}$ (Malagi) environment is most favorable for characters such as seed yield, pod length and number of number of pods per plant whereas $E_{2}$ (Mugad) is suitable for number of number of seeds per pods trait. On the basis of seed yield $\left(\mathrm{kg} \mathrm{ha}^{-1}\right)$ over environments, the $\mathrm{F}_{6}$ lines of DC $15 \times$ CPD118 and DC 15× DCS47-1-2 were found to be most stable. Based on stability parameters, stable genotypes that can be used directly for breeding program are C $152 \times$ IC 202860, DC $15 \times$ CPD 118 and GC $3 \times$ CPD 115 for pod length, C $152 \times$ GL3, DC16 and C $152 \times$ IC 202860 for pod number, C $152 \times$ P 206, C $152 \times$ DCS 5-3-20, DC $15 \times$ Job 129 and DCS 47-1 $\times$ DC 15 for number of seeds per pod respectively.

\section{References}

Adam, J. I., Baidoo P. K., 2008, Susceptibility of five cowpea varieties to attack by 
Callasobruchus maculatus. J. Ghana Sce. Ass., 10 (2): 85-92.

Adewale B. D., Okonji C., Oyekanmi A. A., Akintobi D.A. C. and Aremu C. O., 2010, Genotypic variability and stability of some grain yield components of Cowpea. African J. Agric. Res., 5: 874880.

Akande S. R., 2007, Genotype by environment interaction for cowpea seed yield and disease reaction in the forest and derived savanna agroecologies of south west Nigeria. American-Eurasian J. Agric. Environ. Sci., 2: 163-168.

Ali Y., Aslam Z., Hussain F. and Shakur A., 2004, Genotype and environmental interactions in cowpea for yield and disease resistance. Inter. J. Environ. Sci. Tech., 1: 119-123.

Deshpande, V.K., Makanur, B., Deshpande, S.K., Adiger, S., and Salimath, P.M., 2011, "Quantitative and Qualitative losses caused by Callosobruchus maculates in Cowpea during Seed Storage”. Plant Archi., 11(2): 723-731.
Eberhart S. and Russel W.A., 1966, Stability parameters for comparing varieties. Crop Sci., 6: 36-40.

Rangel, A., Domont, G. B., Pedrosa, C., and Ferreira, S. T., 2003, Functional properties of purified vicilins from cowpea (Vigna unguiculata) and pea (Pisum sativum) and cowpea protein isolate. J. of Agric. Food Chem., 51: 5792- 5797.

Silva, D. O. M., Santos, C. A. F. and Boiteux, L. S., 2016, Adaptability and stability parameters of total seed yield and protein content in cowpea (Vigna unguiculata) genotypes subjected to semi-arid conditions. Australian J. Crop Sci., 10 (8): 1164-1169.

Singh, B.B., 2005, "Cowpea (Vigna unguiculata (L.) Walp.)", In: Singh, R.J. \& Jauhar, P.P. (Eds), Genetic resources, chromosome engineering and crop improvement. Vol. 1. CRC Press, Boca Raton, FL, USA, 117-162.

Uttam, C., Ashok, N. T., Niraj, K., Kul, B. S. and Sunil, C., 2014, Yield stability in pigeon pea hybrids (Cajanus cajan (L.) Mill) under varying agro-climatic regions. Ratar. Povrt, 51(1): 7-17.

\section{How to cite this article:}

Sanjeev K. Deshpande and Vishwas, A.R. 2018. Stability Analysis for Yield and Yield Attributing Characters among Advanced Stabilized Promising Lines in Cowpea [Vigna unguiculata (L.) Walp.]. Int.J.Curr.Microbiol.App.Sci. 7(10): 887-894. doi: https://doi.org/10.20546/ijcmas.2018.710.098 